\title{
Sobrevivendo à Tempestade: a Influência do Tratamento Oncológico de um Filho na Dinâmica Conjugal
}

Surviving the storm:

The influence of the oncologic treatment of a child on the conjugal relation
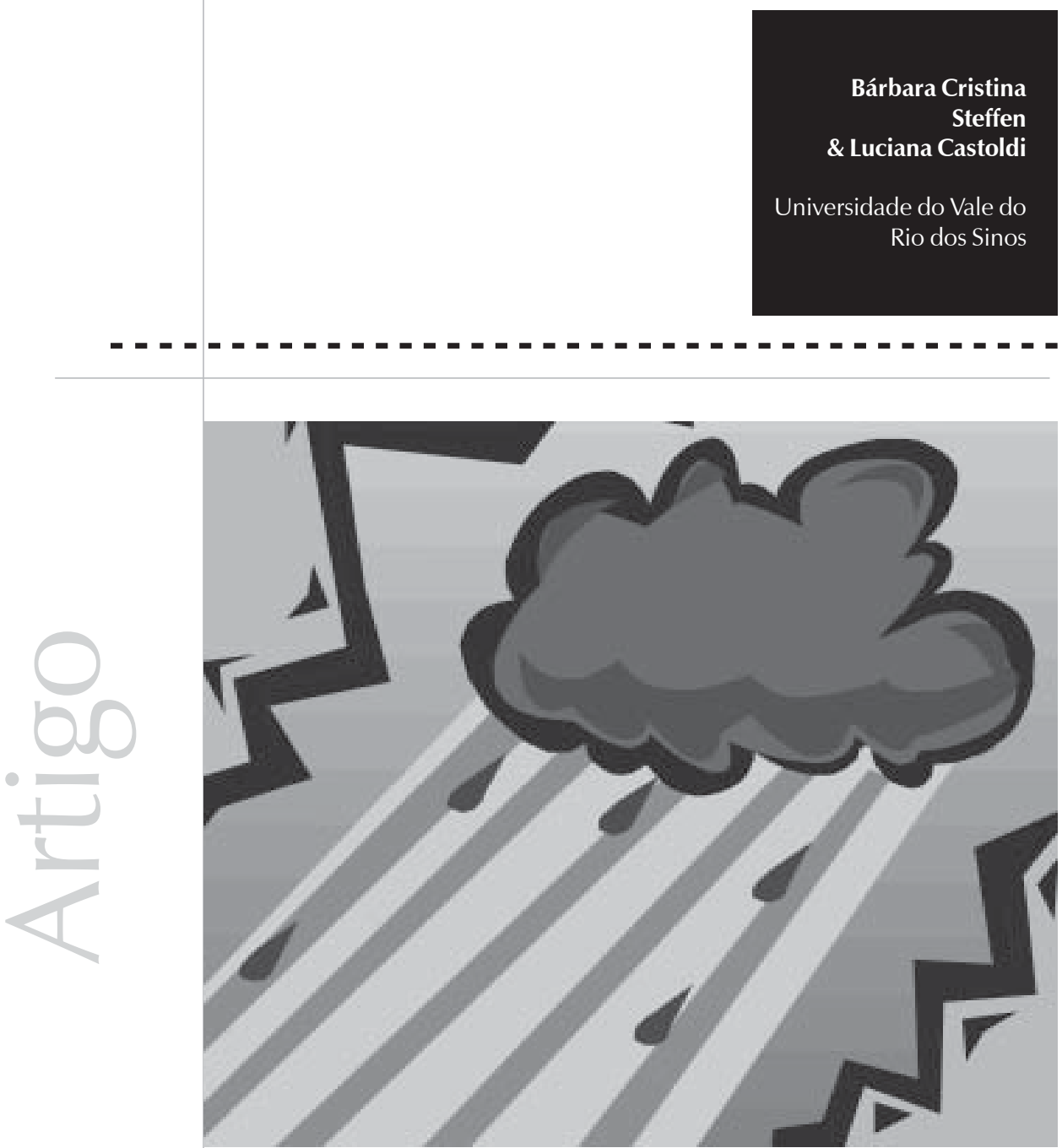


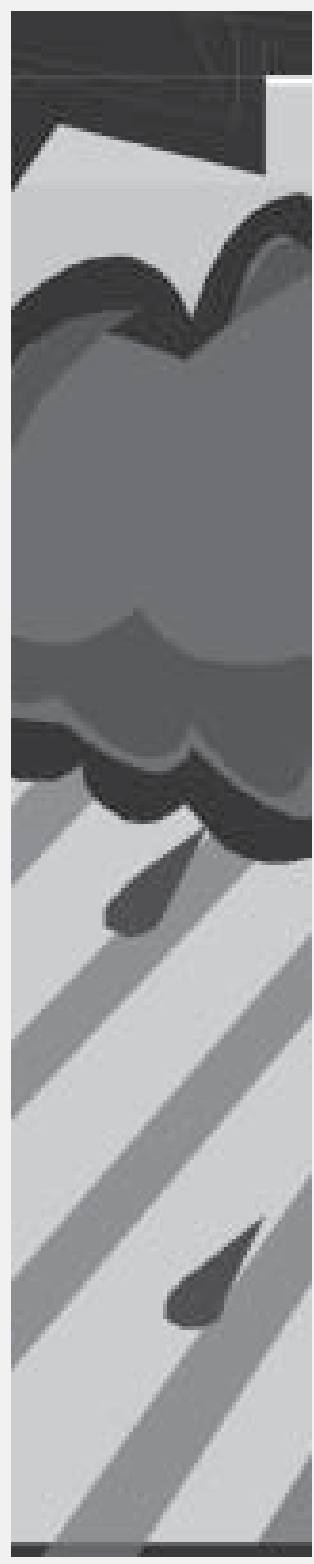

Resumo: O diagnóstico de câncer infantil altera o padrão de funcionamento familiar, fazendo com que a atenção dos pais se concentre sobre o filho doente. Por essa razão, é freqüente a relação conjugal perder espaço, o que pode levar ao aumento da incidência de conflitos entre os cônjuges. O presente estudo tem por objetivo investigar a influência que o acompanhamento do tratamento oncológico do filho exerce sobre a conjugalidade. Para tanto, foi realizada uma pesquisa qualitativa, da qual participaram três casais cujos filhos realizavam tratamento oncológico em um hospital pediátrico. A coleta de dados foi feita por meio de entrevistas semidirigidas, que foram gravadas, transcritas e submetidas à análise de conteúdo. Os resultados encontrados apontam a necessidade de intervenções dentro do âmbito hospitalar no sentido de minimizar conflitos e resgatar a conjugalidade. Este artigo, pois, apresenta algumas possibilidades de intervenção.

Palavras-chave: câncer infantil, conjugalidade, hospitalização, intervenção psicológica.

Abstract:The diagnosis of infantile cancer modifies the family dynamic standard. It makes parents concentrate their attention on the sick child. For this reason, it is frequently realized that the conjugal relationship loses its space, which may increase the incidence of conflicts among the couple. This paper intends to investigate the influence of the parents' accompaniment of the oncologic treatment on the conjugal relation. It is a qualitative research in which three couples, whose children were in oncologic treatment at a pediatric hospital, were enrolled. Data collection was done using semi-directed interviews. The interviews were taperecorded, transcribed and submitted to content analysis. Results show the necessity of interventions in the hospital environment with the objective to minimize conflicts and to rescue the conjugal relation. This paper presents some possibilities of intervention.

Key words: infantile cancer, conjugal relation, hospitalization, psychology intervention.

\section{Considerações iniciais sobre o câncer infantil}

O diagnóstico de uma doença crônica é um evento desestabilizador em qualquer fase do ciclo vital (Lacaz, 2003; Valle, 2001). Quando uma criança é acometida por uma doença grave, o abalo parece ser ainda maior. No caso do câncer infantil, essa realidade, na maioria das vezes, toma grandes proporções, uma vez que o câncer é uma doença carregada de significados pejorativos, vivida ainda como uma fatalidade que elimina a possibilidade de um amanhã (Mazorra \& Tinoco, 2005).

Antes vista como doença fatal, o câncer infantil, atualmente, é considerado uma 
A hospitalização,

que é parte do tratamento oncológico, é o fator responsável por grande parte das modificações inerentes ao tratamento, pois altera tanto o ritmo de vida familiar quanto o desenvolvimento da criança. doença crônica, passível de cura (Mazorra \& Tinoco, 2005). Conforme estudos, o câncer pediátrico apresenta-se como a segunda causa de mortalidade infantil no Brasil. Atualmente, por meio de diagnóstico e tratamento adequados, a taxa de cura tem chegado ao índice de 70\% (Hira; Lopes; Zuffo; Lopes, 2005). Porém, mesmo diante dos resultados da Medicina, a representação simbólica do câncer continua diretamente relacionada à morte e ao descontrole, como se os tratamentos existentes não fossem capazes de estagnar ou curar a doença (Simonton, 1990). O mesmo autor aponta o fato de que tais crenças causam malefícios diretos ao paciente. Enfatiza que, devido à imagem que se tem do câncer, a aceitação da doença fica mais difícil e, em conseqüência, a adesão ao tratamento. A forma como a família recebe o diagnóstico também poderá interferir positiva ou negativamente na aceitação que o paciente terá do tratamento (Pedrosa et al., 2005; Silva, 2000). Segundo Penna (2004), as famílias exercem grande influência sobre o curso da doença no paciente, sobretudo quando este é uma criança. Se bem orientadas, poderão auxiliá-lo na utilização de seus recursos de adaptação de forma mais eficaz, respeitando suas possibilidades e limitações individuais, daí a importância de uma equipe bem qualificada para oferecer ao paciente e sua família o acolhimento de que necessitam.

De um modo geral, o câncer gera crise no grupo familiar (Silva, 2000) porque o 'novo' se apresenta de maneira radical e repentina. A doença impõe ao paciente e sua família mudanças em sua rotina, nos papéis até então desempenhados, exige busca de estratégias para enfrentar o problema, mudança de posturas, atitudes e comportamentos (Eizirik \& Ferreira, 2000). Quando o paciente oncológico for uma criança, seus pais terão de enfrentar uma enormidade de decisões e novidades (Simonton, 1990), o que, de alguma forma, afetará sua vida conjugal. Conforme Walsh (2002), eventos muito estressantes, especialmente aqueles relacionados a possíveis perdas, podem colocar até mesmo o casal mais funcional em sério perigo.

No que tange à vida a dois, dentro do entendimento da teoria sistêmica, quando um casal se constitui, deve formar uma identidade conjugal, com planos conjuntos para o futuro (Labres \& Souza, 2004; Minucchin \& Nichols, 1995). Com a chegada dos filhos, novos movimentos ocorrem no núcleo familiar, havendo, então, a assunção de novos papéis, pois marido e mulher passarão a ser também pai e mãe (Carter \& Mcgoldrick, 2001). Por sua vez, quando um filho é acometido por uma doença crônica, o padrão de funcionamento familiar sofre alterações, fazendo com que todos os membros sejam afetados ao assumir novas responsabilidades. O casal, portanto, passa a ter um leque cada vez maior de situações e emoções a serem administradas, o que não é fácil, sendo que poderão obter sucesso ou não em suas iniciativas.

A hospitalização, que é parte do tratamento oncológico, é o fator responsável por grande parte das modificações inerentes ao tratamento, pois altera tanto o ritmo de vida familiar quanto o desenvolvimento da criança. Em uma internação, a criança passa por agressões físicas e psicológicas devido à utilização necessária de procedimentos invasivos. Por esse motivo, ela tenderá a manifestar mais claramente suas carências afetivas (Chiattone, 2003). Em meio a todos esses acontecimentos, o casal precisa encontrar meios de manter uma relação saudável, o que constitui um grande desafio. Frente a tal realidade, o presente estudo tem o intuito de conhecer e discutir, por meio de pesquisa e experiência clínica, algumas das influências do tratamento oncológico de um filho na relação conjugal para, a partir disso, propor uma modalidade de intervenção que possa auxiliar na promoção de qualidade de 
vida para os casais. Assim sendo, entre os temas abordados, destacamos os impactos decorrentes da notícia diagnóstica, as modificações no padrão de funcionamento do núcleo familiar, a nova realidade vivida a partir da hospitalização da criança, os reflexos sobre a relação conjugal, a importância da rede de apoio, o temor pela possível perda do filho, os desafios da comunicação eficaz e o resgate da conjugalidade. Iniciaremos especificando a metodologia de pesquisa utilizada para, na seqüência, apresentarmos os dados discutidos à luz da teoria.

\section{O caminho percorrido}

\section{Delineamento}

Trata-se de um estudo exploratório, de natureza qualitativa, apresentado no formato de casos múltiplos. O objetivo da pesquisa qualitativa não é a generalização dos dados, mas sim, a análise em profundidade (Minayo, 2000).

\section{Participantes}

Participaram da pesquisa três casais, cujos filhos realizavam tratamento oncológico no Hospital da Criança Santo Antônio (HCSA - RS) ${ }^{1}$ e estavam sendo atendidos por uma das pesquisadoras durante seu estágio profissional. Tratou-se de uma amostra por conveniência, na qual foram incluídos pacientes com idade entre zero e doze anos ("crianças" conforme o ECA, 1990), com quadros clínicos equivalentes e cujos pais residem no mesmo endereço. Para fins de identificação, atribuiremos a cada um dos casais um sobrenome. Destacamos que os nomes de todas as crianças foram alterados. Os pais de Isabela, uma menina de seis anos, portadora de leucemia linfóide aguda ${ }^{2}$ (LLA), serão chamados de casal Rosa; os pais de Emanuelle, seis anos, também portadora de LLA, serão o casal Oliveira, e os pais de Eduarda, cinco anos, portadora de melanoma ${ }^{3}$, casal Pereira.
Instrumentos

A coleta de dados foi feita por meio de entrevistas semidirigidas, realizadas na presença do casal, no ambiente hospitalar. Tratava-se de uma entrevista com três questões, cujo objetivo foi investigar as influências da doença grave infantil na dinâmica conjugal.

Para fazerem parte deste trabalho, os participantes assinaram um termo de consentimento livre esclarecido, autorizando a sua realização, respeitados os aspectos éticos referentes à pesquisa com seres humanos (Resolução no 196/96).

Análise de dados

As entrevistas foram gravadas, transcritas e submetidas à análise de conteúdo, seguindo a teoria de Minayo (2000). Tal metodologia compreende um conjunto de técnicas que visam à análise das comunicações, desmontando a estrutura e os elementos do conteúdo para esclarecer diferentes características e extrair significação. Assim, no presente estudo, foram analisados os conteúdos manifestos e latentes dos discursos e comportamentos dos casais, levando-se em consideração não apenas o momento da entrevista, mas também os atendimentos junto ao leito, realizados ao longo das internações hospitalares. Como referencial de base, foi utilizada a teoria sistêmica, que subsidia a teoria familiar.

\section{Meu filho tem câncer: o impacto da notícia}

O câncer desestabiliza, gerando crises de diversas ordens na vida de todas as famílias (Simonton, 1990; Silva, 2000; Carter \& Mcgoldrick, 2001; Chiattone, 2003). A natureza da crise dependerá, entre outros fatores, do tipo de doença e da dinâmica do grupo familiar (Silva, 2000). Carter e McGoldrick (2001) apontam os diversos ciclos
1 "Este projeto de pesquisa foi autorizado pelo comite de Ética do Complexo Hospitalar Santa Casa de Porto Alegre".

2 Leucemia linfóide aguda: tipo de câncer que ocorre nas células sanguíneas. As células com leucemia não realizam as funções normais do sangue, como o combate à infecção e a coagulação.

3 Melanoma: tipo de câncer de pele com prognóstico ruim. Possui elevada probabilidade de disseminar metástases para outros órgãos. 
"Ao ouvir a notícia, não conseguimos dizer nada. Abraçamo-nos e começamos a chorar" pelos quais passa uma família ao longo da vida (namoro, casamento, nascimento do primeiro filho, família com filhos pequenos, famílias com filhos adolescentes, período do "ninho vazio", retirada da vida ativa - aposentadoria). Por sua vez, Rolland (2001) sugere que, assim como a família passa por ciclos, a doença apresenta fases (crise, crônica e terminal) que exigem novas posturas dos membros no sentido de adaptarem-se e conseguirem viver com qualidade. Salienta, ainda, que, para cada fase, existe uma "tarefa-chave" a ser cumprida. A primeira fase é a de crise, que vai do pré-diagnóstico até o esclarecimento da situação e caracteriza-se por ser uma época de dúvidas quanto à eficácia do tratamento. Valle (2001) denomina o período do diagnóstico como um "tempo de catástrofes", quando o "medo da morte" se torna o pano de fundo para as ações dos pais. A tarefachave dessa fase seria a busca de significados para a doença (Rolland, 2001).

Por meio das entrevistas realizadas, foi possível conhecer de perto o impacto ocasionado pela notícia. Os três casais mencionaram terem sido surpreendidos por ocasião do diagnóstico. Tanto os pais de Isabela quanto os de Emanuelle enfatizaram que suas filhas, até então, eram crianças saudáveis e que jamais esperavam que um dia tivessem uma doença de tal gravidade. Mesmo diante dos sintomas que se tornavam recorrentes, era impossível para os casais suspeitar que pudesse ser câncer. O casal Oliveira, antes de receber a confirmação diagnóstica, já expressou sua surpresa:

"Nós sentimos que algo muito grave poderia estar acontecendo devido à reação do médico (expressão facial), mas nunca imaginamos que pudesse ser uma leucemia" (casal Oliveira).

Mesmo para o casal Pereira - Eduarda já havia nascido com um tumor benigno de pele, por isso, contavam com a possibilidade de um câncer ser desenvolvido - foi grande o choque quando o diagnóstico se confirmou.
A reação apresentada pelos três casais foi de choro e desespero.

"Ao ouvir a notícia, não conseguimos dizer nada. Abraçamo-nos e começamos a chorar" (casal Rosa).

Nenhum casal deseja que seu filho se torne portador de uma doença crônica. Assim, quando é diagnosticado o câncer em um filho, os pais buscam explicações, ficam profundamente impactados e quase sempre demonstram um grande sentimento de culpa pelo aparecimento da doença e pela hospitalização da criança (Chiattone, 2003). Freqüentemente, questionam-se quanto à sua competência genética (Castro \& Piccinini, 2002), sobre a possibilidade de terem exigido demais dos filhos, de terem feito algo de errado durante a gravidez, entendendo, dessa forma, a doença como um castigo pelo erro supostamente cometido (Lacaz, 2003).

O casal Oliveira, ao longo de todos os meses de atendimento, apontava a possibilidade de ter falhado com a filha com relação a sua alimentação. Mesmo após os pais receberem inúmeras explicações médicas, continuavam nutrindo a idéia de que a leucemia de Emanuelle pudesse ser decorrente de uma anemia mal curada.

Ainda quanto à culpabilidade, o casal Pereira buscou, durante muito tempo, explicações junto ao departamento de genética para saber se a filha tinha herdado de algum deles sua doença. Em sua narrativa, revelaram que, enquanto não tiveram certeza da nãohereditariedade do tumor de pele da filha, utilizaram os fatos para fazerem trocas de cobranças emocionais.

Para a compreensão do impacto do diagnóstico sobre a família, é importante considerarmos que, desde antes de nascer, a criança já é depositária de uma série de expectativas, tanto do casal quanto das famílias de origem (Silva, 2000). Um filho representa a capacidade 
criadora dos pais (Lacaz, 2003), a possibilidade de imortalidade, na medida em que ele é a continuação do casal (Casellato, 2002); por isso, instala-se um grande paradoxo no caso das crianças enfermas, pois a dor de constatar que o filho real (com câncer) é diferente do filho imaginado (saudável) deixa profundas marcas no narcisismo dos pais. Com o surgimento da doença, todo um sentido de futuro passa a ser ameaçado, e a família depara-se repentinamente com a possibilidade de perda, de dor e de sofrimento e também com a frustração de não ver concretizados seus anseios (Ramalho, 2002; Lacaz, 2003).

O sentimento de perda está entre os que mais aparecem com o diagnóstico de câncer, isso porque é corrente que os casais tenham perdido algum familiar ou amigo com a mesma doença. Quando a pessoa perdida por câncer é um dos pais do casal, o temor pela perda do filho é ainda maior, podendo iniciar, então, o processo de luto antecipatório (Dóro; Pasquin; Medeiros; Bitencourt; Moura, 2004). O aspecto fundamental desse luto, no caso dos pais que acompanham o tratamento, relacionase ao futuro, antecipadamente destruído, gerando uma alteração brusca no sentido de vida da família (Fonseca, 2002). Exemplo disso é a fala da mãe de Emanuelle no momento em que recebeu o diagnóstico:

"Eu achava que não tinha tratamento para leucemia de criança. Eu imaginei que ia perder minha filha. Foi a primeira coisa que pensei".

Conforme Botelho (2005), junto com a doença, um turbilhão de sentimentos invade o núcleo familiar, mobilizando sua estrutura e dinâmica, alterando seu funcionamento. Em função dessa realidade, Valle (2001) destaca a importância de a equipe ser acolhedora e esclarecer as dúvidas dos pais constantemente, isso porque, na medida em que compreenderem melhor a doença, os pais poderão organizar-se, reduzindo os fatores de estresse, chegando, assim, mais perto do cumprimento da primeira fase, que é a criação de significado para a doença, na tentativa de preservar um sentimento de domínio e competência (Rolland, 2001).

\section{A vida mudou: a família e o tratamento oncológico}

Com o início do tratamento, hábitos mantidos durante anos pela família são modificados para que se dê conta da terapêutica do filho doente (Simonton, 1990; Silva, 2000). Em decorrência disso, ocorre a ruptura da identidade familiar, prévia ao diagnóstico de câncer (Damasio \& Rúmen, 2005). É então que se pode pensar que não só a criança se torna vítima do câncer, mas também sua família (Valle, 2001).

Desde a forma como a notícia é transmitida até o final do tratamento, tudo irá interferir no impacto que o diagnóstico exercerá sobre o paciente e seu núcleo familiar (Silva, 2000; Rolland, 2001; Chiattone, 2003). Penna (2004) sugere que, assim como existem diferentes tipos de câncer, também existem diferentes tipos de famílias. Dessa maneira, esse impacto ocasionará conseqüências específicas em cada uma delas (Carter \& Mcgoldrick, 2001).

Quanto a alterações de rotina dos casais entrevistados, constatou-se que estes tiveram uma redução de atividades em sua vida social. Antes, com a criança saudável, o casal Rosa estava habituado a sair para jantar, ir a festas, receber os amigos em casa ou ir ao seu encontro, e Isabela costumava acompanhá-los. Da mesma forma, o casal Oliveira destacou o tradicional passeio dos finais de tarde, quando levavam Emanuelle para andar de bicicleta, na praça, enquanto aproveitavam para conversar e tomar chimarrão.

Com o advento da doença, os três casais tiveram de restringir passeios e visitas no intuito de proteger a saúde das crianças. O casal Pereira, por sua vez, afirmou que, ao longo dos anos de casados, nunca tiveram o hábito
"Eu achava que não tinha tratamento para leucemia de criança. Eu imaginei que ia perder minha filha. Foi a primeira coisa que pensei". 
"Uma das

mudanças é que a gente passa mais tempo aqui (no hospital) do que fora; não podemos, por exemplo, participar de muitas promoções festivas que

acontecemem nossa cidade porque não estamos lá". de sair, fazer programações com outros casais, e, portanto, não perceberam grandes mudanças no que tange à sua vida social. Salientaram, no entanto, as transformações ocorridas em sua vida decorrentes do nascimento de Eduarda. A partir daquele momento, passaram a freqüentar médicos em razão do tumor benigno, doença com a qual nasceu a menina e que desencadeou o câncer. Aqui vale observar que, entre os entrevistados, esse terceiro casal foi o que revelou estar atravessando problemas de ordem conjugal desde o período anterior ao nascimento da filha. Nesse caso, o câncer agravou substancialmente a situação.

Damásio e Rumen (2005), em seus estudos, afirmam que o diagnóstico de câncer de um filho é uma fase de crise que afeta especialmente o relacionamento conjugal. Dizem também que existe grande tendência de que o casal passe a enfrentar uma série de desencontros em função do contexto. Considerando que o desejo de reciprocidade seja a tônica de um casal, realidades como o câncer podem afetar significativamente a relação (Anton, 1998).

Quanto à rotina, portanto, os entrevistados reconheceram que alguma alteração aconteceu, haja vista que precisaram adaptarse às freqüentes hospitalizações. Para tanto, acabaram modificando a forma de relacionarse com o restante da família e com seus compromissos. Concernente a esse aspecto, o casal Rosa falou sobre suas atividades:

"Uma das mudanças é que a gente passa mais tempo aqui (no hospital) do que fora; não podemos, por exemplo, participar de muitas promoções festivas que acontecem em nossa cidade porque não estamos lá".

A vida social, de um modo geral, é substituída por constantes visitas ao médico, sendo necessário que os pais permaneçam atentos às medicações e hospitalizações da criança. Como conseqüência disso, todos aqueles que convivem com o doente acabam sendo atingidos (Castro \& Piccinini, 2002).
Observamos, entretanto, o quanto as pessoas não estão preparadas ou não conseguem imaginar como reorganizar suas vidas após o diagnóstico do filho. O câncer é um 'desconhecido' que invade a privacidade familiar e conjugal: chega sem pedir licença e coloca as pessoas frente a situações com as quais não sabem lidar. Pela prática clínica, constata-se que, diante do diagnóstico, a maioria dos casais fica perdida, sem saber o que fazer e quais as ações priorizar. Quando a porta de entrada da criança no hospital é a UTI, tudo fica ainda mais complicado, porque o medo de perder o filho se torna mais real. Ao iniciar o tratamento, obtém-se a maior prova de que a notícia é verdadeira e que não foi um mero engano de diagnóstico. Dessa forma, se até então a doença vinha sendo negada, agora será necessário deparar-se com ela e começar a agir.

Ao falar sobre a negação, que ocorre em muitos casos, experimentada pelos membros da família, Le Shan (1992) afirma que, até certo ponto, existem benefícios na negação do tipo 'saudável', equivalente a uma "crosta" de proteção que se constitui nos momentos mais críticos. Com o passar do tempo, no entanto, é preciso dissolvê-la. Ressalta o autor que a equipe deve estar atenta, caso essa negação seja do tipo prejudicial, ou seja, quando se cristalizar num mecanismo de longa duração, pois isso enfraqueceria o relacionamento pessoal dos familiares para com o paciente, podendo acarretar problemas de diversas ordens.

\section{A criança hospitalizada: conseqüências para as relações familiares e conjugais}

Segundo Castro e Piccinini (2002), a doença crônica pode ser vista como um estressor que afeta o desenvolvimento normal da criança e atinge as relações sociais dentro do sistema familiar. Chiattone (2003) afirma que, quando o câncer aparece em uma criança, provoca brusca interrupção no seu desenvolvimento. $\mathrm{O}$ afastamento do ambiente doméstico e 
escolar torna-se necessário, em função de longos períodos de internação, provocando, em muitos casos, a desorganização do mundo interno da criança e de seus cuidadores. Devido a todas as novidades inseridas no seu cotidiano (medicamentos, exames, consultas e diversos procedimentos invasivos), o pequeno paciente experiencia novas sensações, tais como medo, sensação de punição, despersonalização, regressão no seu desenvolvimento psicológico e cognitivo (Camon, 1997; Chiattone, 2003), o que leva os pais a sentirem-se, muitas vezes, despreparados para lidar com o próprio filho. Entre os fatos acima citados, a regressão vivida pela criança é um dos que mais chama a atenção, tanto dos pais quanto da equipe médica. Sobremaneira por ocasião do diagnóstico, quando tudo é novo, observa-se que os pais se sentem desautorizados frente à criança e demonstram muita dificuldade para continuarem dando limites a ela. É como se, de uma hora para outra, nada mais soubessem, estando todo o conhecimento e capacidade cuidadora nas mãos da equipe médica. Se antes eram eles que determinavam o que a criança poderia ou não fazer, agora terão de perguntar primeiro ao médico. Isso, sem dúvida, interfere na relação pais-filho e na auto-estima dos genitores - devido à sensação de terem 'desaprendido' de cuidar do próprio filho.

O câncer, por ser um evento altamente estressor, tende a alterar a estrutura do relacionamento entre os cônjuges, podendo levar a conflitos (Damasio \& Rumen, 2005). Para visualizar isso, é interessante estarmos atentos aos movimentos que as famílias fazem naturalmente ao longo de seu ciclo vital. A dinâmica conjugal é modificada quando nasce um filho, pois ele inaugura um novo período na vida dos esposos (Carter \& Mcgoldrick, 2001). Sabe-se que, a partir do nascimento, o pequeno ser humano precisará ser educado. E, se já é difícil para o casal entrar em consenso na educação de um filho saudável, maior é o desafio quando ele é portador de uma doença crônica. Minucchin e Nichols (1995) ressaltam que conflitos não-resolvidos entre os cônjuges são facilmente carregados para dentro da área de educação infantil pelo fato de o casal não conseguir separar as funções parentais das funções conjugais. Além disso, para os pais, é complicado ter de lidar com tantas transformações que ocorrem visivelmente na criança (queda do cabelo, perda de peso, sonolência, enjôos) e ainda assim permanecerem tranqüilos e saber o que é melhor para ela. Se não houver alguma estabilidade conjugal, portanto, é provável que não suportem juntos tamanha dor.

Castro e Piccinini (2002) sugerem que a família precisa adaptar-se à nova realidade de convívio com seu membro enfermo. Salientam também que as relações familiares são fundamentais para o adequado enfrentamento da doença, reforçando que a família pode servir como moderadora na atenuação dos efeitos negativos da patologia ao promover para a criança um ambiente facilitador para o progresso de seu tratamento. No intuito de evitar situações mais desgastantes, Silva (2000) sugere que o ideal é a família ir modificando lentamente seu estilo de vida.

\section{Lidando com as novidades: os movimentos familiares e a busca de equilíbrio}

Passadas as turbulências iniciais, quando a família caminha para um ajustamento de seu padrão de funcionamento, começa a segunda fase, a fase crônica (Rolland, 2001). Essa é a época do tratamento propriamente dito, quando períodos de maior otimismo são intercalados pela ameaça de perda, sendo a incerteza o sentimento que prevalece (Silva, 2000). Walsh e McGoldrick (2000) chamam a atenção para o fato de que, quanto mais a doença evolui, maior é o número de familiares que podem experimentar e manifestar sua raiva, ciúme e carências. Tais sentimentos, 
"Eu acho que a distância judia muito". E sua esposa complementou "É, ele contava que sentia muita saudade de nós e é assim até hoje. Ele diz que chega em casa do trabalho e não tem vontade de fazer nada. Ele fica em casa, se encerra, se deita. Quantas vezes eu liguei e perguntei 'o que tu estás fazendo?' e ele me disse 'ué, o que eu vou estar fazendo? Estou deitado"'. decorrentes da ameaça de perda que o câncer suscita, podem levar também ao aparecimento de um sintoma em outro membro da família. A tarefa-chave da fase crônica, segundo Rolland (2001), seria o restabelecimento de uma certa autonomia entre os membros, na tentativa de equilibrar as necessidades das pessoas sãs com as do membro doente, buscando manter uma vida o mais normal possível, apesar da doença. Segundo Pedrosa et al. (2005), a manutenção dessa 'normalidade' é o maior desafio enfrentado pelas famílias.

No Hospital da Criança Santo Antônio, muitas das crianças atendidas são provenientes do interior do Estado. Para fazerem o tratamento, viajam quilômetros e permanecem muitos meses longe de casa. Então, quando o tratamento evolui, uma das novidades de rotina é o distanciamento físico que ocorre na maioria dos núcleos familiares. Um dos primeiros movimentos é o afastamento do trabalho de um dos pais, que passa a acompanhar integralmente as hospitalizações do filho. Normalmente é a mãe que assume esse papel, mas, cada vez mais, os pais têm participado ativamente de todo o processo. Existe, contudo, a necessidade de que um dos genitores permaneça exercendo suas atividades profissionais no intuito de garantir o sustento familiar. Ocorre aí a primeira grande separação: mãe e criança doente de um lado, pai e filhos saudáveis de outro. Nas entrevistas, os três casais mencionaram dificuldades e sofrimento decorrentes de tal separação. O pai de Isabela afirmou:

"Eu acho que a distância judia muito". E sua esposa complementou "É, ele contava que sentia muita saudade de nós e é assim até hoje. Ele diz que chega em casa do trabalho e não tem vontade de fazer nada. Ele fica em casa, se encerra, se deita. Quantas vezes eu liguei e perguntei 'o que tu estás fazendo?' e ele me disse 'ué, o que eu vou estar fazendo? Estou deitado'".
Antes do câncer, essa não seria a atitude normal do pai da menina, pois ele é bastante comunicativo e habitualmente vai ao encontro das pessoas. A saudade é uma das marcas da distância. No caso de Isabela, tanto a menina quanto a mãe sempre sentiram muita falta do pai e da irmã, que passou a morar com outros familiares durante o tratamento.

\section{Rede de apoio: uma necessidade}

O que observamos na prática clínica é que, para lidar com a separação do núcleo familiar, quando o casal tem outros filhos, faz-se necessário contar com uma rede de apoio, sobretudo com a família ampliada (avós, tios, madrinhas), para que eles assumam os cuidados para com as outras crianças. Todavia, nem sempre as famílias têm com quem contar. Há diversos casos em que as mães precisam 'dividir' seu tempo entre o hospital e o cuidado das outras crianças que, por vezes, são menores do que aquela que está hospitalizada, e isso acaba tornando-se mais um evento estressor. Percebe-se claramente que as famílias que contam com rede de apoio têm maior probabilidade de superarem os obstáculos do câncer com sucesso.

Entre os casos estudados, o casal Rosa foi o que demonstrou ter uma rede de apoio melhor constituída. Segundo seu relato, quando estão na sua cidade, podem contar com a avó de Isabela ou alguma de suas tias para que possam trabalhar. Por sua vez, durante as internações, contam com amigos (um dos quais lhes cedeu um apartamento para utilizarem durante todo o período de tratamento da filha). Isso garante que o pai da menina possa permanecer um período mais longo junto dela e de sua esposa. Quanto aos benefícios da presença do pai, a mãe revelou:

"Quando o pai está aí, é ele que faz o almoço dela, e ela sente-se mais segura, porque não gosta da comida do hospital. Então, o pai tem 
que estar aqui para fazer a comida, para lavar a roupa dela. E mais, ele consegue fazer com que ela coma. Ele mostra para Isabela o carinho com que prepara a comida. Eu também me sinto muito melhor quando ele está aqui; assim podemos dividir as preocupações".

Nesse caso, fica evidente a necessidade existente e os benefícios que a rede de apoio pode proporcionar. Além disso, quando o casal está perto, dividindo as preocupações, responsabilidades e decisões, a 'carga' fica mais leve para ambos os cônjuges. Isso é o que se espera de uma família com funcionamento saudável: que os pais partilhem a liderança, se respeitem e tomem decisões em conjunto (Simonton, 1990).

É preciso destacar, no entanto, que nem todos contam com tal apoio. Há casais que, além de ter de enfrentar a doença do filho, ainda precisam lidar com as cobranças e malentendidos que surgem por parte dos familiares. O casal Oliveira passou por uma dessas situações.

"Desde que a gente soube que a Emanuelle tem leucemia, tentamos preservar a saúde dela, e por isso, à noite, tomamos alguns cuidados; se está frio, não saímos. Se as defesas dela estão muito baixas, procuramos evitar contato com outras pessoas. Por isso, chegamos a ter certo conflito na família, sobretudo no início, quando todos queriam visitá-la e nós tivemos de limitar um pouco. Eles já entenderam errado, pois acharam que não queríamos que fossem lá".

Fatos como esse podem fazer com que os pais se sintam sozinhos, e, ainda mais, culpados, já que percebem que não existe compreensão por parte do seu núcleo familiar, podendo chegar ao ponto de isolarem-se do convívio social, não buscando apoio. Góngora (2002) adverte que tal atitude deixa o doente ainda mais vulnerável a transtornos emocionais, o que produz novos problemas para o enfrentamento de sua patologia.
Pesquisas recentes têm mostrado que o apoio social recebido pelas famílias com crianças doentes tende a ser menor do que o apoio social de famílias com crianças saudáveis (Castro \& Piccinini, 2002). Contrapondo tal realidade, verifica-se que é fundamental tanto para o paciente quanto para sua família que sejam beneficiados pela rede social de apoio e recebam suporte no transcorrer de todo o tratamento (Dóro et al., 2004). Diante desses dados, começa a ficar evidente a necessidade de uma equipe acolhedora, que minimize a falta de rede de apoio e que auxilie os membros da família na superação dos obstáculos impostos pelo câncer.

\section{O casal: \\ sentimentos contraditórios}

Quanto às conseqüências do distanciamento físico que ocorre entre os casais em virtude das hospitalizações, outros sentimentos também se fazem presentes, além da saudade acima citada. Um deles é a sensação de nãoreciprocidade. É durante os atendimentos, no desabafo dos pais, que se constata, reiteradamente, a divergência na percepção de maridos e esposas. É freqüente que os cônjuges tenham visões diferentes quanto aos papéis mais fáceis e mais difíceis de serem assumidos durante o tratamento do filho. Como normalmente é a mãe que abre mão da vida profissional para acompanhar a criança doente, ela é a pessoa que mais se comunica com a equipe, que teoricamente mais sabe sobre o prognóstico e apresenta maior destreza para lidar com os acontecimentos. O marido, por sua vez, vai trabalhar, precisa concentrar-se nas atividades, porém, sem desligar-se totalmente do tratamento do filho. Nesse sentido, pode ocorrer um descompasso entre o casal quando um acha que seu sofrimento é maior do que o do cônjuge e, em conseqüência, os dois podem vir a sentirem-se desamparados.

Conforme Damásio e Rumen (2005), seguidamente sentimentos e emoções não 
coincidem, porque cada um tem suas prioridades e seu modo de compreender os fatos. Quanto à diferença de entendimento entre os companheiros, o pai de Emanuelle declarou (casal Oliveira):

"Eu vou puxar pro meu lado. Eu acho que quem está fora sofre mais. Tu não sabes o que está acontecendo. Tu queres correr para cá (hospital), mesmo que tu saibas que não vais ajudar, mas tu desejas estar junto".

A mãe da mesma criança contestou:

"Mas te põe no meu lugar. Tu vais pra casa, tu sais, tu choras, tu colocas para fora, e eu não. Eu estou aqui, assistindo a tudo; eu não posso nem chorar perto dela, não posso colocar meus sentimentos para fora".

Ao longo das entrevistas, os casais tiveram "Mas te põe no meu lugar. Tu vais pra casa, tu sais, tu choras, tu colocas para fora, e eu não. Eu estou aqui, assistindo a tudo; eu não posso nem chorar perto dela, não posso colocar meus sentimentos para fora". oportunidade de se manifestar e, entre eles, a temática das diferenças de percepção apareceu de forma semelhante. Não raro, ao lidar com a doença do filho, os casais iniciam uma 'competição', buscando descobrir quem sofre mais. Essa disputa pode transformar-se num problema, na medida em que divide forças e coloca o casal numa relação de rivalidade e não de união. Exemplo disso é o casal Pereira. Durante a entrevista, a mãe de Eduarda raras vezes olhou em direção ao marido. Suas palavras continham um certo ar de cobrança, sendo perceptível sua dificuldade de colocar-se no lugar do cônjuge e tentar entender sua dor. Numa de suas falas, mencionou que o marido acreditava que ficar no hospital era uma maravilha, opinião essa que não lhe agradava. Porém, ao ouvir o relato da esposa, o pai da menina começou a chorar, sendo visível que as palavras proferidas pela esposa não condiziam com o verdadeiro sentimento experimentado por ele. A sra. Pereira, no entanto, estava tão fechada em suas percepções que não conseguia ouvir o que o marido tinha a dizer.
Segundo Valle (2001), dependendo do grau de ajustamento familiar anterior à doença, o câncer de um filho poderá apenas exacerbar uma situação que já era delicada, havendo um risco de aprofundamento da fratura conjugal (Damasio \& Rumen, 2005).

No que diz respeito à qualidade da relação que antecede o diagnóstico, Silva (2000) sugere que o nível de diferenciação conjugal irá interferir, quer dizer, quanto mais baixo for o nível de diferenciação dos cônjuges (quanto menos maduros forem, quanto menos se perceberem pessoas únicas, diferentes de seus pais e de seu companheiro, responsáveis por suas escolhas), menos capazes serão de expressar diretamente um para o outro suas idéias e sentimentos ansiogênicos sem ficarem zangados ou perturbados. Quanto mais indiferenciados eles forem, portanto, mais provavelmente surgirão conflitos conjugais.

Ao estendermos tal reflexão para o campo psicanalítico, outras compreensões se tornam possíveis. Segundo Freud, a união conjugal está a serviço da satisfação de desejos inconscientes. A mulher busca no marido um substituto paterno, que lhe dê proteção e que, ao mesmo tempo, aceite ser cuidado por ela como se fosse seu filho. Por sua vez, o homem tende a procurar na esposa uma mulher maternal, que lhe dê carinho e satisfaça suas necessidades. É seu intuito, também, que ela o admire e queira ser por ele protegida, tal como uma filha na relação com o pai (Anton, 1998). Sob o olhar psicanalítico, essa seria a origem de uma relação. A felicidade, portanto, poderia ser encontrada com o constante ajuste desses desejos. Toda essa dinâmica é problematizada quando o casal, além de ter de lidar com a presença dos filhos nessa relação, precisa adaptar-se à realidade do câncer infantil.

Nos exemplos citados, e em outros casos atendidos em virtude da enfermidade oncológica do filho, muitas vezes a criança 
acaba constituindo mecanismos de desvios de problemas conjugais, ficando triangulada nos conflitos (Minucchin \& Nichols, 1995). Assim, aparentemente, a situação fica mais fácil para os casais que estão passando por dificuldades, pois, quando se olha para o filho doente, não resta muito tempo para voltar o olhar para a relação. As longas e freqüentes internações, no entanto, geram grande desgaste emocional, acarretando uma carga adicional sobre o subsistema parental que, em muitos casos, já estava desequilibrado. As conseqüências disso podem ser desastrosas, por vezes levando os casais ao divórcio, e tendem a atingir a criança enferma (Silva, 2000).

Destacamos, então, a diferença de atitude entre os dois casais (Oliveira e Pereira). Enquanto no casal Pereira a esposa (cuidadora oficial durante as hospitalizações) não conseguiu sintonizar-se com a dor do marido, a esposa do casal Oliveira compreendeu de outra forma e passou a auxiliar seu companheiro:

"A situação dele era terrível, porque ele não participava dos momentos aqui no hospital com ela. Ele estava fora, estava trabalhando, mas não conseguia nem se concentrar no serviço porque não sabia o que estava se passando aqui."

No início do tratamento, quando o pai de Emanuelle chegava ao hospital, não conseguia conter suas emoções e chorava diante da filha. Era então sua esposa que o confortava, ajudavao a sair do quarto e a restabelecer-se para poder ver a menina. Esse é, sem dúvida, um comportamento de grande valor quando se trata de uma criança portadora de uma doença crônica, uma vez que o funcionamento familiar exerce influência direta sobre a forma como a criança lida com sua enfermidade (Meijer \& Oppenheimer, 2002). Assim, dependendo da mensagem que os pais transmitem ao pequeno doente, ele manifestará reações de segurança ou medo frente ao câncer. Além de preservar a criança, o casal que se apóia ganha forças ao unir-se para lutar em favor da vida do filho.

Importante salientar que, na prática, o que se percebe é que a forma como os pais agem com a criança e como se relacionam também depende da fase na qual a doença se encontra (aguda, crônica ou terminal). Se a criança está melhor, respondendo ao tratamento, brincando, os pais conseguem agir com maior naturalidade, sendo mais objetivos em suas ações e mais coesos e assertivos em sua relação conjugal. Entretanto, quando existe um avanço no sentido da cronicidade, novo abalo familiar se institui, exigindo novas adaptações, nem sempre atingidas com sucesso. Nesse momento, constata-se maior dificuldade entre os familiares para dar o suporte de que o paciente necessita, pois esses também se fragilizam. Infelizmente, não existe estabilidade no tratamento oncológico: há dias em que a criança está bem e há outros em que apresenta piora significativa, e é preciso lidar com isso.

\section{As incertezas presentes}

Os seres humanos, de um modo geral, fazem de tudo para ter o controle sobre suas vidas, e, quando uma enfermidade - como a oncológica - acomete uma pessoa, esse desejo torna-se inviável.

No enfrentamento do câncer infantil, podese propor que existam pontos facilitadores e dificultadores. Entre os pontos facilitadores, citamos a capacidade que as crianças têm, devido ao seu momento de desenvolvimento cognitivo, de continuarem brincando, divertindo-se e alegrando-se em pequenos momentos de prazer, mesmo durante as longas internações. Na maioria das vezes, elas é que 're-energizam' os pais para seguirem lutando. Exemplo disso é a habilidade que têm de, ao freqüentar a sala de recreação do hospital, fazerem novas amizades e mergulharem num mundo de fantasias que faz com que consigam 
sentir-se crianças normais, brincando como as outras que não têm a mesma doença. Constata-se, assim, que as crianças têm maior facilidade de levarem uma vida normal, mesmo estando enfermas. Por menores que sejam, no entanto, elas perguntam quando voltarão para casa, e o sofrimento que demonstram ao ouvir as respostas dos adultos faz com que os pais se sintam ainda mais culpados por tudo o que acontece com elas. Não raro, nos corredores das enfermarias, ouvimos pais nos dizendo: "Queria que fosse comigo"; "Queria poder amenizar a dor do meu filho'. Entre marido e esposa, muitas vezes é difícil suportar tudo isso. Dependendo do nível de estresse experimentado, a união entre o casal poderá ficar abalada. Salientase, no entanto, que o câncer, por si só, não une ou separa um casal. O que ele faz é inaugurar um momento novo, uma crise familiar, que poderá ser entendida como oportunidade (de reestruturação da vida) ou como perigo de desintegração (Silva, 2000). Nesse sentido, há pesquisas que apontam a correlação existente entre estresse emocional e psicopatologia no casal. Como já foi mencionado, o somatório de eventos estressantes decorrentes do câncer pode ocasionar sérios conflitos conjugais. Há estudos, contudo, que relatam a adaptação bem sucedida, que também acontece e é o que se deseja alcançar (Damasio \& Rumen, 2005).

Entre os casais pesquisados, encontramos as diferentes realidades: um casal ficou mais afastado emocionalmente após a doença da filha; outro estabeleceu uma relação de dependência do marido para com a esposa; um terceiro demonstrou ter aumentado significativamente a união conjugal. Este estudo apresenta os principais aspectos verificados na maioria dos pais atendidos no hospital. Nos casos mais graves, constata-se uma separação emocional em que marido e esposa ficam distanciados, cada um com sua dor, não havendo partilha. Anton (1998) chama a atenção para esse isolamento afetivo que compromete a relação. Situações como essa necessitam de intervenção psicológica mediadora com maior urgência para evitar o agravamento de algo que já está instalado no modo de funcionamento conjugal. Por outro lado, existe um dado mais positivo, que é o fato de muitos casais se unirem a partir do diagnóstico de câncer do filho. Contudo, se avaliarmos o teor dessa união, verificaremos que os cônjuges constroem, freqüentemente, uma relação de dependência, ou seja, um deles toma uma posição mais assertiva e o outro se apóia nele para tomar suas decisões. É o caso dos pais de Emanuelle. Como o marido ficou muito inseguro diante do diagnóstico, passou a telefonar para a esposa diversas vezes ao dia, a fim de tomar conhecimento da situação da filha. Há que se destacar que suas ligações não tinham o objetivo de transmitir apoio à companheira, e sim, de aliviar sua própria ansiedade.

Observou-se algo um pouco diferente com os pais de Isabela. Com base no acompanhamento realizado ao longo de oito meses, foi possível averiguar que também sentem a necessidade de entrar em contato um com o outro para tomar decisões mais sérias (o que é saudável no quesito divisão de responsabilidades). Todavia, ao invés de uma relação de dependência, parecem ter chegado mais perto de uma relação de ajuda mútua. Ao falar sobre as mudanças acarretadas a partir da doença da menina, afirmaram:

"Nossa união ficou até mais forte. Um apóia o outro; nós somos muito companheiros. Quando ele não está aqui, eu fico muito insegura e fico sempre ligando e ele também me liga para saber das novidades".

Existe insegurança nesse casal, assim como em todos os outros, mas é algo que podemos considerar dentro de um limite aceitável, esperado. 
Diante de uma doença crônica, que pode levar à terminalidade, a expectativa de modo algum seria de que os pais se sentissem tranqüilos o tempo inteiro. Tal comportamento é que despertaria preocupação, considerando que sempre há um risco de morte iminente. Destacamos que, para a família ultrapassar os obstáculos decorrentes do tratamento e para a criança ter o respaldo de que necessita, o casal precisa estar unido, mesmo na dor, para superar os problemas. A maior dificuldade aparece justamente quando só um dos cônjuges dá força ao outro e não encontra no companheiro alento para sua dor.

\section{A intimidade ainda tem vez?}

Outra questão que está entrelaçada com as alterações da união entre o casal são os efeitos sobre a sua intimidade. Por ter de destinar a maior parte do tempo aos cuidados do filho doente, não resta tempo para encontros íntimos. Não se trata apenas de uma questão de tempo, mas também de disposição para tal. O casal Pereira é exemplo disso. Desde que foi diagnosticado o câncer de Eduarda, há dois anos, eles vivem muito afastados, não só física, mas emocionalmente. Conforme relato da mãe, o casal já passou por diversas crises, sendo que, em alguns momentos, ela conseguiu explicitar para o marido sua dificuldade de separar a preocupação nos momentos íntimos. O pai da menina, por sua vez, admitiu que, no começo, não compreendia a postura da esposa, que demonstrava não sentir nenhum desejo sexual: "No começo eu não entendia e ficava malhumorado. Foi depois de um tempo que eu comecei a ver as razões disso". O casal deixou claro que até hoje essa é uma questão que interfere diretamente, pois, considerando que a saúde da filha se encontra num momento delicado, sua atenção está totalmente focada nela.

A experiência dos pais de Emanuelle, no que tange à intimidade, não é muito diferente, pois a filha passou a dormir no quarto com a mãe e o marido mudou-se para o quarto da filha. Conforme o pai da garota, a vida íntima do casal foi anulada quase que por completo. Sendo o amor genital considerado parte importante na vida conjugal, a ausência desse tipo de afeto possivelmente interferirá na relação (Anton, 1998).

Castro e Piccinini (2002) explicam que os pais de crianças enfermas sentem seus papéis parentais muito mais exigidos do que nas situações em que a criança é saudável, e isso acaba colocando a relação marital num plano inferior de importância para eles. A vida da criança - sua sobrevivência - fica em primeiro lugar. Conseguir dialogar sobre os problemas íntimos acarretados pela doença consiste em uma tarefa essencial para garantir o sucesso conjugal. Nas entrevistas, contudo, ficou claro que os casais apresentam grande resistência para tocar no assunto, abordando-o somente quando não estão mais suportando a situação. Frente a essa realidade, torna-se urgente uma intervenção psicológica que os auxilie a encontrar formas saudáveis de lidar com a situação.

\section{O desafio da comunicação}

Sabe-se que a comunicação eficaz é capaz de reduzir conflitos e promover a coesão e o apoio mútuo (Penna, 2004). Por sua vez, quando começam a ocorrer distúrbios nesse âmbito, há grandes chances de conflitos e confrontos se originarem. Rolland (2001) salienta que há que se considerar que homens e mulheres têm modos diversos de funcionamento, influenciados pelos papéis tradicionais desempenhados por cada sexo. Segundo o autor, normalmente as mulheres desejam mais discutir os próprios sentimentos em relação aos problemas médicos do que as questões concretas referentes à doença.

No entendimento de Walsh (2002), é de fundamental importância que o sistema de 
"Eu não sei se eu sou egoísta, não sei como vou definir meus sentimentos, mas parece que ele não sente como eu sinto. A gente não compartilha os mesmos sentimentos". crenças seja partilhado entre os cônjuges, ou seja, que um diga para o outro que idéia faz da doença e quais são seus principais medos, para que tenham sucesso no relacionamento, mesmo diante das adversidades. Labres e Souza (2004), em concordância, afirmam que, em todos os casos, e sobretudo naqueles em que o casal conta com um filho doente, fazse necessário que exista empatia no relacionamento, ou seja, que um consiga colocar-se no lugar do outro para tentar compreender os sentimentos que perpassam a relação. Caso contrário, a tendência é que enfrentem sérios problemas, que se refletirão na saúde da criança.

Quanto à comunicação conjugal, é freqüente casais que acompanham filhos hospitalizados sentirem dificuldade de partilhar suas emoções, uma vez que não estão mais juntos com a mesma assiduidade. O comentário da mãe de Eduarda serve de exemplo:

"Eu não sei se eu sou egoísta, não sei como vou definir meus sentimentos, mas parece que ele não sente como eu sinto. A gente não compartilha os mesmos sentimentos".

Diante das adversidades impostas pela doença, nem todos os casais conseguem comunicar-se bem. Constata-se, com relação a isso, que, quanto maior é o nível de estresse vivido, maiores são as chances de ocorrerem falhas na comunicação. Tanto a comunicação verbal quanto a não-verbal ficam comprometidas em decorrência da dor, e o cônjuge passa a ter dificuldade de fazer a 'leitura' dos sinais de seu consorte (Anton, 1998).

Nos casais entrevistados, posicionamentos diferentes foram manifestados quanto ao tema. Os pais de Isabela enfatizaram:

"Desde o início de nosso relacionamento, temos o hábito de conversar sobre tudo. Partilhamos todas as coisas um com o outro. $E$ depois da doença da Isabela não foi diferente. Atualmente, quando ele não está conosco no hospital, passo as informações por telefone. Quando estamos juntos, cada um manifesta seus sentimentos e a gente tenta se ajudar".

Verificou-se que esse casal tinha um bom padrão de funcionamento quando foi diagnosticado o câncer da filha, e esse é um aspecto que facilita a boa comunicação e a resolução de problemas entre os cônjuges durante o tratamento. Mesmo com tantos aspectos positivos, observou-se, no período em que a família foi atendida, que existiram momentos em que a mãe de Isabela não conseguiu comunicar ao marido seus medos reais quanto ao estado de saúde da filha. Tal fato coincidiu com a internação da menina na UTI durante 20 dias, período mais crítico do tratamento. Quando a dor pela possível perda aumentou, a comunicação diminuiu. Isso ocorre freqüentemente entre os pais. Percebese que não têm coragem de mencionar a possibilidade de perda, como se o simples fato de partilharem suas idéias fosse suficiente para torná-las reais. Exemplo disso é o relato da mãe da paciente num dos atendimentos na sala de espera da UTI:

"Sou uma pessoa bastante reservada. Contigo converso bastante, mas, com as outras pessoas, não consigo me abrir. Nem para meu marido consegui dizer o que senti nestes últimos dias".

O relato acima demonstra que, mesmo em situações conjugais favoráveis, frente a eventos estressores inerentes à doença, a comunicação pode tornar-se falha.

Dentro do mesmo tema, o casal Oliveira, pais de Emanuelle, destacou a grande mudança que aconteceu a partir do câncer: "A comunicação entre a gente ficou péssima". Conforme o casal, a grande dificuldade existente entre eles foi justamente a forma muito diversa de compreender e lidar com a doença. Enquanto a mãe tentava manter-se bem diante da filha 
e confiava nas explicações médicas, o pai demonstrava seus medos na frente da menina e não conseguia aliviar sua culpa quanto à origem da doença. Sendo assim, inúmeras vezes ocorreram desentendimentos entre o casal. Com o casal Pereira, a situação pareceu ser um pouco mais delicada. Ambos desabafaram dizendo que esperariam do seu companheiro maior abertura para o diálogo. Ao conectarmos a linguagem verbal desse último casal com a não-verbal, constatamos que fica evidente o desligamento emocional. Em seus gestos, não foi possível perceber nenhuma manifestação de carinho. Pelo contrário, o que se observou foi a inexistência de empatia reforçada pela nítida desautorização que a mãe faz da figura do pai. Ela defendeu convictamente a posição de que não adiantaria fazer nada pela relação dos dois. Ao tecer uma análise, a sensação é a de que o caos se instalou e não há investimento nem mesmo em palavras (diálogo) para devolver um pouco de vitalidade à relação. Isso se tornou evidente quando a mãe de Eduarda falou:

"Sinceramente, eu não sei o que fazer para melhorar. Chegou uma hora onde parece que eu desisti. Parece que pra mim tanto faz como tanto fez".

Realidades como essa, em que o câncer é diagnosticado num momento de crise conjugal, tornam-se preocupantes, pois, se os pais vierem a deparar-se com a perda do filho, provavelmente enfrentarão problemas ainda mais sérios em sua relação marital.

\section{Sobrevivendo à tempestade: o resgate da conjugalidade}

Falar sobre a relação nem sempre é tranqüilo. Nesse sentido, um fato marcante no decorrer deste estudo foi verificar que os pais apresentaram grande resistência em abordar diretamente temas concernentes à conjugalidade. Os três casais detiveram-se nos detalhes do diagnóstico, no impacto causado, mas não se concentraram na questão central que estava sendo investigada. Isso nos faz pensar que a doença absorve tanto os pais que, embora as dificuldades conjugais existam e sejam importantes, eles não conseguem falar sobre o assunto. A partir de tais constatações, iniciamos uma reflexão com base na pergunta: o que se pode fazer enquanto a criança está hospitalizada para prevenir conflitos conjugais e promover qualidade de vida para os casais? A literatura que se dedica ao tema do câncer normalmente aborda a vivência da doença no núcleo familiar como um todo, mas raramente adentra no mundo conjugal. Entretanto, pela experiência clínica, percebe-se que não basta olhar apenas para o grupo. Faz-se necessário lançar o olhar sobre a conjugalidade que é significativamente afetada.

Com as mudanças bruscas de vida e a necessidade de revisão dos modos habituais de comunicação e funcionamento do grupo familiar que o câncer impõe, muitos casais se sentem perdidos e apresentam dificuldades para encontrar soluções saudáveis para seus problemas. Se considerarmos que a criança enferma é fortemente influenciada pelos pais, torna-se urgente que a família desenvolva a capacidade de ser continente, de acolher e lidar com as dores que aparecem na trajetória do tratamento. Sob essa ótica, Valle (2001) enfatiza que ambientes familiares nos quais sejam permitidas expressões de sentimentos, sem excesso de conflitos, são os mais favoráveis para o surgimento de melhores condições de enfrentamento.

A partir dos dados coletados, verificou-se que desde as menores alterações na rotina da família até os problemas mais sérios, tudo é influenciado pela capacidade de comunicação do casal. Ratificando tal constatação, Silva (2000) afirma que a comunicação não só transmite informações, como também impõe um comportamento, um jeito de ser. Levando em consideração essa afirmação, buscam-se 
formas de evitar que cada um dos cônjuges se enclausure em sua dor e se distancie emocionalmente tanto do filho enfermo quanto dos demais membros da família.

Cada vez fica mais clara a necessidade de uma intervenção psicológica que auxilie os pais a encontrar maneiras flexíveis e criativas para lidarem satisfatoriamente com os problemas que surgem ao longo do tratamento, preservando sua relação. Castro e Piccinini (2002) acreditam que os pais necessitam de oportunidades para falar sobre suas preocupações e medos. Em concordância com tais autores, Dolgin e Phipps (2001) sugerem que, quanto mais o casal externalizar seus sentimentos, maiores serão as chances de identificação de fatores que predisponham a respostas saudáveis. Para Walsh (2002), os casais precisam ser ajudados na construção de novas capacidades interativas, sendo que uma das possibilidades seria a realização de sessões terapêuticas formais (Minde, 2002). Existe consenso entre os autores de que toda a equipe que atende a criança tem poder de influência sobre seu tratamento e sobre sua família. De acordo com Castro e Piccinini (2002), é necessário que os profissionais da saúde estejam atentos aos aspectos que transcendem o tratamento médico da doença da criança. Destacam também que há evidências de que intervenções qualificadas podem ajudar todo o grupo familiar a lidar de maneira satisfatória com as conseqüências psicológicas e sociais associadas ao câncer.

Integrando teoria e prática, podemos pensar que uma das possibilidades para o resgate da conjugalidade seria, justamente, a implantação de um serviço psicológico de acompanhamento aos pais dos pacientes com câncer, desde o momento do diagnóstico. Sabe-se que muitos hospitais já oferecem atendimento psicológico ao paciente e seus familiares; contudo, o foco predominante permanece colocado sobre a doença. A não ser em casos extremos, não faz parte da terapêutica tratar de assuntos associados à conjugalidade. O procedimento adotado, caso seja identificado algum problema na relação, é o encaminhamento para serviços de psicologia externos ao hospital. Não há, portanto, nenhum incentivo para que os profissionais (e estagiários de Psicologia) adentrem no universo dos cônjuges.

Diante da constatação antes mencionada, de que os casais tendem a não investir na relação durante o tratamento oncológico, uma alternativa é potencializar a conjugalidade, ou seja, promover ações que facilitem o encontro e o resgate dos sentimentos entre os cônjuges. É nesse aspecto, então, que este trabalho pretende inovar. Propõe-se aqui que os pais sejam atendidos enquanto casal, ou seja, que, além dos aspectos referentes à doença e aos seus papéis parentais, seja feito um acompanhamento no ambiente hospitalar com especial atenção dedicada à relação conjugal. Por meio de experiência clínica, verificou-se que, dentre as famílias que participaram da pesquisa, o casal que foi acompanhado desde o início, com ênfase na relação marital, foi o que encontrou soluções mais saudáveis para as dificuldades enfrentadas enquanto a filha estava realizando tratamento.

Existem diversas vantagens proporcionadas pela implantação do atendimento ao casal. Com a mediação do psicólogo, a expressão de sentimentos entre os cônjuges é facilitada; o casal consegue dar-se conta de suas atitudes de distanciamento emocional, iniciando uma busca por alternativas mais saudáveis. Por meio do contato mais íntimo proporcionado pelas sessões terapêuticas, o profissional poderá investigar o simbolismo do câncer na família, compreendendo de forma mais objetiva os impactos que o diagnóstico exerce sobre seus membros. Os encontros freqüentes também permitem que os pais compreendam os passos do tratamento do filho e que se conscientizem de seus temores e fantasias. Além disso, eles facilitam a aproximação da família com a equipe 
médica, pois o psicólogo, enquanto integrante da equipe oncológica, poderá mediar esclarecimentos entre os pais e o médico que, devido ao grande número de pacientes sob sua responsabilidade, muitas vezes conta com tempo restrito para dar atenção a cada um. Ainda no que tange aos benefícios do atendimento, a constância dos encontros permitiria que as informações com relação ao diagnóstico fossem trabalhadas paulatinamente, de modo a preparar os pais emocionalmente para cada nova fase do tratamento.

Salienta-se, todavia, que uma intervenção na conjugalidade requer preparo adequado. É preciso que se conheça em profundidade as teorias e técnicas psicológicas voltadas ao casal para que a abordagem seja feita de maneira correta. Caso contrário, ao invés de proporcionar maior qualidade, ela poderá destruir os laços ainda existentes. O que estamos propondo não é resolver todos os problemas do casal, mas sim, orientá-los para que o rompimento da relação não seja mais uma das conseqüências do câncer do filho.

Não apenas o profissional da área psicológica mas também toda a equipe multiprofissional têm a contribuir na busca de qualidade de vida para o paciente e sua família. Damásio e Rumen (2005) admitem a existência de seqüelas inevitáveis acarretadas pelo tratamento, porém enfatizam que elas poderão ser minimizadas por meio de ações de cuidado com essas famílias, reforçando atitudes que as confortem, amparem e fortaleçam, despertando a esperança na restauração do sentido da vida familiar, seja durante o tratamento, seja na recidiva, seja na cura, ou mesmo diante do luto. Sendo assim, os profissionais que atendem crianças com câncer devem estar aptos a lidar com a angústia e o medo do desconhecido, inerentes à doença (Pedrosa et al., 2005).

É fato que, quando a equipe dá a devida atenção aos pais, todos são beneficiados, e, a partir disso, pode-se pensar na existência de um sistema inter-relacionado. Assim, sugerese que o casal, quando recebe apoio psicológico e atenção da equipe, passa a confiar nos profissionais e transmite segurança ao filho. Sentindo-se mais seguro, o paciente participará do tratamento de maneira mais tranqüila, dificultando menos os procedimentos, o que, em conseqüência, reduzirá seu sofrimento. Por sua vez, quando começam a aparecer resultados positivos no tratamento da criança, os pais normalmente assumem uma postura mais esperançosa, alcançando maior estabilidade emocional. Então, a tendência é que haja diminuição de estresse e conflitos familiares. Logo, todo o grupo familiar sairá ganhando.

A operacionalização dessa proposta não requer grande esforço. O essencial é que os profissionais da área psicológica se preparem de maneira adequada (com teoria e supervisões). Outra questão que se aborda diz respeito ao setting hospitalar, que se apresenta de modo bem diferente daquele instituído pela clínica tradicional. Porém, lidar com isso é parte da rotina do psicólogo que já atua em organizações hospitalares. O que muda, então, é que, além dos atendimentos ao leito realizados com a criança e seus familiares, farão parte do programa de atendimento psicológico sessões exclusivas para o casal. Vale observar que, ao contrário de muitas intervenções realizadas nos corredores do hospital, esse é um atendimento que requer privacidade, portanto, o indicado é que se procure uma sala onde a sessão ocorra com o mínimo de interrupções. Poderá ser um consultório médico, uma sala de conforto ou outro ambiente que ofereça aos pais tranqüilidade para abordarem aspectos de sua vida privada. Ainda com relação às vantagens da proposta de atendimento, cabe destacar que, ao longo de nossa experiência clínica, deparamo-nos com diversos casais que visivelmente necessitam de acompanhamento psicológico. Todavia, quando são encaminhados para um profissional externo ao hospital, muitas vezes 
demonstram resistência, encontrando os mais variados motivos para não buscarem ajuda especializada. A realidade dentro do ambiente hospitalar mostra-se contrária. Por mais que exista algum tipo de oposição quando se coloca o serviço à disposição, em pouco tempo o casal constata os benefícios que a atenção do psicólogo produz em seu filho e adere de bom grado às sessões terapêuticas.

O que se deseja, em última instância, é que tanto as crianças quanto seus pais sejam amplamente beneficiados com o acompanhamento psicológico para que a passagem pelo tratamento oncológico seja uma fase o menos traumática possível em suas vidas.

\section{Considerações finais: o sol voltará a brilhar?}

"Sensibilidade: eis um instrumento que deverá estar sempre presente entre aqueles utilizados no ambiente hospitalar".
O casamento promove a união de duas pessoas que sonham em encontrar a felicidade juntas. Para muitos casais, os filhos representam um dos aspectos fundamentais para a concretização dessa felicidade. Quando alguma coisa "dá errado" ou foge aos padrões convencionais, como ocorre com o adoecimento grave e prolongado de uma criança, as bases da conjugalidade podem ser profundamente abaladas.

Considerando os temas até aqui abordados, percebemos que o câncer infantil é uma doença com grande poder de mobilização, uma vez que fragiliza não apenas a criança enferma, mas também seus familiares e os profissionais que a atendem. Trabalhar com tais pacientes faz com que repensemos nossos valores. Talvez uma das maiores dificuldades experimentadas pelos pais que acompanham o tratamento oncológico de um filho seja visualizar o futuro, encontrando algum sentido para suas próprias vidas depois de tamanho abalo.

Por meio da pesquisa realizada, constatou-se que há diferentes caminhos a serem trilhados pelos casais. Cabe a eles fazer suas escolhas, porém existem sinais que indicam uma possível direção: casais que recebem apoio tendem a superar suas dificuldades de forma mais criativa, rápida e eficiente.

O impacto e as mudanças de rotina resultantes do diagnóstico podem provocar a ruptura da identidade familiar anterior à doença, o que exerce influência na relação do casal. A experiência por eles vivida poderia ser comparada a uma verdadeira tempestade. $\mathrm{O}$ céu escurece quando os sintomas começam a aparecer na criança. Depois, em meio a raios e trovoadas, o diagnóstico é confirmado. Em seguida, o vento do medo devasta sonhos e convicções, e, quando a chuva cai, surgem dúvidas, pois não se sabe o que fazer. Ajudar os pais a sobreviver a essa tempestade é uma das tarefas do psicólogo hospitalar.

A experiência junto à oncologia pediátrica nos mostra que a família é a grande motivadora do tratamento das crianças, pois ela é capaz de transformar seu novo mundo, por hora balizado pelo câncer, num lugar onde sonhos e fantasias ainda têm vez. Em alguns momentos, os pais poderão não saber onde encontrar motivação e, para isso, o psicólogo estará ao seu lado.

Se, com nossa intervenção, conseguirmos ajudar a família a enxergar algum raio de sol e se o brilho dessa luz puder iluminar o casal, fazendo com que a claridade do amor reapareça em sua relação, todo nosso esforço terá valido a pena.

Sensibilidade: eis um instrumento que deverá estar sempre presente entre aqueles utilizados no ambiente hospitalar. É ele que nos ajudará a ver que, por trás de cada paciente, existe uma história; por trás de cada luta, um desejo, e, para além do desejo, existe vida.

A todas as crianças que nos ensinaram que a vida sempre pode surpreender-nos e a seus pais, que permitiram que esta pesquisa fosse realizada, nosso agradecimento e o desejo de que a 'claridade do amor' seja a grande luz a brilhar em sua relação. 
Bárbara Cristina Steffen

Psicóloga graduada pelo Curso de Psicologia da UNISINOS. Av. Inconfidência 700/302. Bairro: Marechal Rondon. CEP: 92020-320. Canoas/RS. E-mail: psi.barbara@gmail.com Fone: (51)3051-1107 ou (51)9143-9949

Luciana Castoldi Professora orientadora. Doutora em Psicologia do Desenvolvimento (UFRGS). Docente da Universidade do Vale do Rio dos Sinos

Recebido 06/02/06 Reformulado 12/06/06 Aprovado 14/06/06

ANGERAMI- CAMON, Valdemar Augusto (org). Psicologia Hospitalar ANGERAMI- CAMON, Valdemar Augusto (org). Psicologia Hospitalar : Teoria e Prática. São Paulo : Pioneira, 1997, 3ạ ed.

ANTON, lara L. Camaratta. A Escolha do Cônjuge: um Entendimento Sistêmico e Psicodinâmico. Porto Alegre: Artmed, 1998.

BOTELHO. In Perina, Elisa (org). As Dimensões do Cuidar em Psiconcologia Pediátrica. Campinas: Livro Pleno, 2005.

BRASIL. Lei Federal no 8.069, de 13 de julho de 1990. ECA - Estatuto da Criança e do Adolescente. Disponível em: http:// www.planalto.gov.br/ccivil 03/Leis/L8069.htm Acesso em: 05 maio 2005.

BRASIL. Resolução no 196, de 1996. Diretrizes e Normas Regulamentadoras de Pesquisas Envolvendo Seres Humanos. Conselho Nacional de Saúde. Disponível em:

http://www.bioetica.ufrgs.br/res196ch.htm. Acesso em: 20 maio 2005.

CASELLATO, Gabriela. Luta pela Perda de um Filho: a Repercussão Possível diante do Tipo de Perda. In Franco, M. H. P. Uma Jornada sobre o Luto: a Morte e o Luto sob Diferentes Olhares. Campinas: Livro Pleno, 2002.

CASTRO, Elisa Kern; PICCININI, César Augusto. Implicações da Doença Orgânica Crônica na Infância para as Relacões Familiares: algumas Questões Teóricas. Psicologia, Reflexão e Crítica, v. 15, n. 3. Porto Alegre: 2002, pp. 625-635.

CARTER, Beth; MCGOLDRICK, Mônica. As Mudanças do Ciclode Vida Familiar: uma Estrutura para a Terapia Familiar. Porto Alegre: Artes Médicas, 2001, 2- ed.

CHIATONNE, Heloísa Benevides. A Criança Hospitalizada. In AngeramiCamon, Valdemar Augusto (org). A Psicologia no Hospital. São Paulo: Pioneira Thomson Learning, 2003. $2^{\mathrm{a}} \mathrm{ed}$

DAMASIO, Ângela; RUMEN, Frida. Mães na Assistência à Criança com Câncer: o Enfrentamento sem a Figura Paterna em Casa de Apoio. In Perina, Elisa (org). As Dimensões do Cuidar em Psiconcologia Pediátrica. Campinas: Livro Pleno, 2005.

DOLGIN e PHIPPS. In Valle, Elizabeth R. M. (org). Psico-oncologia Pediátrica. São Paulo: Casa do Psicólogo, 2001.

DÓRO, Maribel P.; PASQUIN, Ricardo; MEDEIROS, Carlos R. BITENCOURT, Marco Antônio; MOURA, Glaci L.. O Câncer e sua Representação Simbólica. Psicologia Ciência, v. 24, n.2, 2004, pp.120134

EIZIRIK \& FERREIRA In Silva, Célia Nunes. Comoo Câncer(Des)Estrutura a Família. São Paulo: Annablume, 2000.

FONSECA, J.P.; FONSECA, M. I. Luto Antecipatório. In Franco, M. H. P. Estudos Avançados sobre o Luto. Campinas: Livro Pleno, 2002.

GÓNGORA, J. N. In Castro, Elisa Kern; Piccinini, César Augusto. Implicações da Doença Orgânica Crônica na Infância para as Relações Familiares: algumas Questões Teóricas. Psicologia, Reflexão e Crítica, v. 15, n. 3. Porto Alegre: 2002, pp. 625-635.

HIRA, Adilson; LOPES, Thiago; ZUFFO, Marcelo; LOPES, Roseli. Oncopediatria: Projeto de Telesaúde em Oncologia Pediátrica. ayhira@Isi.usp.br.Laboratório de Sistema Integráveis. Universidade de São Paulo. Disponível em:

$<$ http://www.hu.ufsc.br/IX CIBS/trabalhos/arquivos/781.pdf > Acesso em 05 maio de 2005.

LABRES, Carmen Lúcia de Souza; SOUZA, Patrícia Pacheco. Uma
Correlação entre Comunicacão e Resiliência nos Casais. Pensando Famílias, ano 6, n.7. Porto Alegre, 2004, pp.29-34

LACAZ, Cristiane Pessoa. Descortinando o Universo: a Família da Criança com Câncer. São Paulo: Cabral, 2003.

LESHAN, Lawrence. O Câncer como Ponto de Mutação : um Manua para Pessoas com Câncer, seus Familiares e Profissionais de Saúde. São Paulo: Summus, 1992, 1 a $\mathrm{e}$ ed.

MAZZORRA, L.; TINOCO, V. Luto na Infância: Intervenções Psicológicas em Diferentes Contextos. Campinas: Livro Pleno, 2005.

MEIJER; A. M.; OPPENHEIMER, L. In Castro, Elisa Kern; Piccinini, César Augusto. Implicações da Doença Orgânica Crônica na Infância para as Relacões Familiares: algumas Questões Teóricas. Psicologia, Reflexãoe Crítica, v. 15, n. 3. Porto Alegre: 2002, pp. 625-635.

MINAYO, Maria Cecília de Souza. O Desafio do Conhecimento: Pesquisa Qualitativa em Saúde. São Paulo: Hucitec, 2000.

MINDE, K. In Castro, Elisa Kern: Pccinini, César Augusto. Implicacões da Doença Orgânica Crônica na Infância para as Relacões Familiares: algumas Questões Teóricas. Psicologia, Reflexão e Crítica, v. 15, n. 3. Porto Auestões Teóricas. Psicologit

MINUCCHIN, Salvador; NICHOLS, Michael P. A Cura da Família: Histórias de Esperança e Renovação Contadas pela Terapia de Família. Porto Alegre: Artes Médicas, 1995.

PEDROSA, Arli; PEDROSA, Francisco; PEDROSA, Thais F; PEDROSA Silvia F. Comunicação do Diagnóstico do Câncer Infantil. In Perina, Elisa (org). As Dimensões do Cuidar em Psiconcologia Pediátrica. Campinas: Livro Pleno, 2005

PENNA, Therezinha L. M. Dinâmica Psicossocial de Famílias de Pacientes com Câncer. In Mello Filho, Julio e Bird, Miriam (org). Doença e Família, cap. 23. São Paulo: Casa do Psicólogo, 2004, pp. 379- 389

RAMALHO, M. A. N. Psico-oncologia e Luto: Crianças com Câncer. In Franco, M. H. P. Uma Jornada sobre o Luto: a Morte e o Luto sob Diferentes Olhares. Campinas: Livro Pleno, 2002.

ROLLAND, Jonh S. Doenca Crônica e o Ciclo de Vida Familiar. In Carter, B. e Mcgoldrick, Mônica. Ass Mudanças do Ciclo de Vida Familiar: uma Estrutura para a Terapia Familiar. Porto Alegre: Artes Médicas, 2001 2a ed.

SIMONTON, Stephanie Matthews. A Família e a Cura: o Método Simonton para Famílias que Enfrentam uma Doença. São Paulo: Summus, 1990.

SILVA, Célia Nunes. Como o Câncer (Des)Estrutura a Família. São Paulo: Annablume, 2000.

VALLE, Elizabeth R. M. (org). Psico-oncologia Pediátrica. São Paulo: Casa do Psicólogo, 2001.

WALSH, Froma. Casais Saudáveise Casais Disfuncionais: qual a Diferenç? In Andolfi, Maurizio. A Crise do Casal: uma Perspectiva Sistêmicorelacional. Porto Alegre: Artmed, 2002.

WALSH, Froma; MCGOLDRICK, Mônica. In Silva, Célia Nunes. Comoo Câncer (Des)Estrutura a Família. São Paulo: Annablume, 2000.

Leucemia Linfóide Aguda: Abrale - Associação Brasileira de Linfoma e Leucemia.

Disponível em : http://www.abrale.org.br/doencas/leucemia/lla.php Acesso em: 15 jul. 2005.

Melanoma Maligno. Dermatologia.net Disponível em:

http://www.dermatologia.net/neo/base/Doencas/melanoma.htm Acesso em: 15 jul. 2005. 